This is the author's final, peer-reviewed manuscript as accepted for publication. The publisher-formatted version may be available through the publisher's web site or your institution's library.

\title{
Tallgrass prairie soil fungal communities are resilient to climate change
}

Ari Jumpponen and Kenneth L. Jones

\section{How to cite this manuscript}

If you make reference to this version of the manuscript, use the following information:

Jumpponen, A., \& Jones, K. L. (2014). Tallgrass prairie soil fungal communities are resilient to climate change. Retrieved from http://krex.ksu.edu

\section{Published Version Information}

Citation: Jumpponen, A., \& Jones, K. L. (2014). Tallgrass prairie soil fungal communities are resilient to climate change. Fungal Ecology, 10, 44-57.

Copyright: @ 2013 Elsevier Ltd and The British Mycological Society

Digital Object Identifier (DOI): doi:10.1016/j.funeco.2013.11.003

Publisher's Link: http://www.sciencedirect.com/science/article/pii/S1754504813001141

This item was retrieved from the K-State Research Exchange (K-REx), the institutional repository of Kansas State University. K-REx is available at http://krex.ksu.edu 
Tallgrass prairie soil fungal communities are resilient to climate change

ARI JUMPPONEN ${ }^{1,2^{*}}$ and KENNETH L. JONES 3

Ari Jumpponen

1 Division of Biology, Kansas State University, Manhattan, KS66506, USA

2 Ecological Genomics Institute, Kansas State University, Manhattan, KS66506, USA

3 University of Colorado School of Medicine, Aurora, C080045, USA

* Corresponding Author

Keywords: altered precipitation; global warming; soil fungi; tallgrass prairie

Article history:

Received

Revision received

Accepted

Corresponding editor: 


\begin{abstract}
Climate models for central United States predict increasing temperatures and greater variability in precipitation. Combined, these shifts in environmental conditions impact many ecosystem properties and services. Long-term climate change experiments, such as the Rainfall Manipulation Plots (RaMPs), can be used to address soil community responses to simultaneous manipulation of temperature and temporal variability in precipitation. The RaMPs experiment is located in a native tallgrass prairie at the Konza Prairie Biological Station and has been operational since 1998 providing the potential to address responses to long-term environmental manipulations. To test whether community composition, richness, or diversity respond to environmental change, more than 40,000 fungal amplicons were analyzed from soil samples collected in 2006. The data suggest that soil fungal communities are compositionally resilient to predicted environmental change. This is the case both for the community composition overall as inferred from ordination analyses as well as analyses of variance for each of the most common Operational Taxonomic Units (OTUs). However, while this study suggests compositional resilience, further studies are required to address functional attributes of these communities and their responses to environmental manipulations.
\end{abstract}




\section{Introduction}

Water and temperature are major abiotic factors that influence grassland carbon exchange on an ecosystem level both above- and belowground (Xu et al. 2004; Davidson \& Jansens 2006). These factors are also fundamental drivers of the heterotrophic respiration that is estimated to account for $30-50 \%$ of the total soil respiration in most terrestrial systems (Raich \& Schlesinger 1992; Bond-Lamberty et al. 2004), although estimates may vary widely depending on biome/ecosystem (compare Hanson et al, 2000; Wan \& Luo 2003; Chen et al. 2009). The significance of the soil respiration and the large contribution of soil-inhabiting microbial communities to $\mathrm{CO}_{2}$ flux emphasize their importance and underline the need to better understand the compositional and functional attributes of these communities, particularly so in the face of predicted future environmental conditions (Bargett et al. 2008; Drigo et al. 2008).

Grasslands are important biomes. They comprise approximately $32 \%$ of the natural vegetation of earth's surface (Adams et al. 1990) and store 28-37\% of the terrestrial organic soil carbon (Lal 2004). The function and composition of the plant communities in grassland ecosystems have been proposed to be sensitive to variability in climatic conditions (Knapp \& Smith 2001; Gao \& Reynolds 2003). In grassland ecosystems, shifts in timing of precipitation - not in the total quantity can be important controls of plant productivity (Knapp et al. 2002; Fay et al. 2011), soil respiration (Harper et al. 2005; Fay et al. 2011), as well as function and structure of soil communities (Zeglin et al. 2013). As soil moisture and its variability are major controls of the broad scale function and composition of the soil communities on various spatial (Brockett et al. 2012) and temporal scales (Zeglin et al. 2013), more detailed evaluation of community responses to long-term manipulations are timely. 
IPCC (2007) predicted that effects of changes in extreme events - both increases in the duration of droughts and in the per event precipitation volumes - may exceed those expected for changes in average precipitation leading to more variable precipitation regime and soil moisture in mesic ecosystems (Knapp et al. 2008). While such changes in the per event volume of rainfall as well as in their frequency have been suggested to lead to rapid alterations in soil processes as well as aboveground community composition (Knapp et al. 2002; Fay et al. 2003; Harper et al. 2005; Swemmer et al. 2007; Fay et al. 2011), consequences of such alterations for belowground microbial communities have received comparatively less attention (Chou et al. 2008; Zeglin et al. 2013). This major gap prohibits our understanding of the soil community responses to changes in soil water that far exceed those witnessed for dominant plants (Huxman et al. 2004; Ogle \& Reynolds 2004; Schwinning \& Sala 2004), tend to be more dynamic, and responsive to pulse events (Austin et al. 2004; Ogle \& Reynolds 2004; Carbone et al. 2011).

While both water and temperature are major abiotic controls of grassland ecosystem carbon exchange (Xu et al. 2004; Davidson \& Jansens 2006; Fay et al. 2011), the effects of altered precipitation are not as well understood as those of elevated $\mathrm{CO}_{2}$ or temperature (Weltzin et al. 2003). Studies focusing on the interactions of multiple global change drivers may be fewer yet (Bardgett et al. 2008). The responses to interacting climatic drivers of soil communities and their function tend not to be additive (Shen et al. 2009; Hayden et al. 2012; Matias et al. 2012). Accordingly, experimental manipulations that combine multiple global change factors are necessary to elucidate the potentially synergistic responses of soil systems. Increased soil temperatures tend to stimulate soil respiration directly through positive responses by acceleration of both autotrophic and heterotrophic metabolism (Rustad et al. 2001; Melillo et al. 2002; Shen et al. 2009). Alternatively, higher soil temperatures may shift soil function indirectly through increases in nitrogen mineralization, primary production, and litter production (Stromgren \& Linder 2002; Pendall et al. 2004). Warming may also reduce overall microbial biomass (Frey et al. 2008) and increase (Castro et al. 2010) or decrease (Allison \& 
Treseder 2008; Hayden et al. 2012) fungal abundance. Overlaid with changing average temperatures, changes in soil water potential may directly and indirectly control soil community metabolic and physiological activities by affecting substrate availability via litter production and substrate diffusion (Skopp et al. 1990; Davidson \& Janssens 2006; Bardgett et al. 2008). Warming may amplify these effects - potentially as a result of greater rate of water loss from the soil profile. Sheik et al. (2011) reported that with elevated temperatures, water budgets regulated microbial populations. More importantly, they concluded that timing of the precipitation events is critical for microbial populations.

In contrast to broad microbial community responses to environmental manipulations, few studies have explored the responses of general soil fungal communities - particularly to interacting environmental factors. Fungal community responses to warming would be expected, because fungal respiration tends to increase with temperature (Hacskaylo et al. 1965; Malcolm et al. 2008) although in the long-term the communities may adapt to the changing environmental conditions (Malcolm et al. 2008). Studies that have targeted the effects of elevated temperature have reported different and contrasting responses (Bardgett et al. 1999; Compant et al. 2010): experimental warming may increase diversity of soil fungi (Allison \& Treseder 2008), decrease (Allison \& Treseder 2008; Hayden et al. 2012) or increase (Castro et al. 2010; Ziegler et al. 2013) fungal abundance or biomass, change relative taxon abundances (Allison \& Treseder 2008; Deslippe et al. 2011; Anderson et al. 2013), or have minimal effects on richness, diversity, and community composition (Allison et al. 2010; Papanikolaou et al. 2010) depending on the ecosystem. In addition to the ecosystem level context dependencies (Compant et al. 2010), interacting environmental drivers may further modulate the fungal community responses (Hayden et al. 2012). For example, Rygiewicz et al. (2000) showed that soil fungal community responses to elevated temperature differed between [ $\left.\mathrm{CO}_{2}\right]$ treatments. Heterotrophic fungal communities and their responses to shifts in environmental conditions are particularly important, because they are essential in 
carbon and nutrient cycling (Dighton 2003), comprise a large recalcitrant belowground carbon sink (Treseder \& Allen 2000), and may be affected directly by the shifts in the environmental drivers or indirectly through the responses in plant communities (Cregger et al. 2012). Anderson et al. (2013) observed that both elevated $\mathrm{CO}_{2}$ and elevated temperature influenced the fungal community composition. These authors emphasized the importance of considering the community responses in the context of the plant host, as decoupling direct effects of environmental conditions and indirect effects modulated via plant communities are essential to understand the complexities of soil community dynamics (Bardgett et al. 2008). The plant community dependent responses are particularly important for root-colonizing mycorrhizal communities. Studies focusing on those fungal guilds have reported increases in ecto- and arbuscular mycorrhizal mycelium, species richness, as well as root colonization in response to experimental warming (Staddon et al. 2003; Clemmensen et al. 2006; Heinemyer et al. 2006; Hawkes et al. 2008; Deslippe et al. 2011; Büscher et al. 2012), although these responses are unlikely to be universal (Olsrud et al. 2010). Experimental warming may also lead to shifts in the relative abundances of soil inhabiting fungi and bacteria (Zhang et al. 2005; Rinnan et al. 2007; Frey et al. 2008).

Soil moisture also strongly influences fungal communities structurally and functionally (Toberman et al. 2008; Bell et al. 2009; Baldrian et al. 2010; Castro et al. 2010; Hawkes et al. 2011; Schmitt \& Glaser 2011; Cregger et al. 2012). Variability in soil moisture may shift biomass or ratios of fungi and bacteria within a growing season (Clark et al. 2009; Gray et al. 2011; Cregger et al. 2012; Baldrian et al. 2013), in response to pulse events (Fierer et al. 2003; Zeglin et al. 2013), or in response to experimental manipulations of soil moisture (Nazih et al. 2001; Cregger et al. 2012; Zeglin et al. 2013). Some recent studies have suggested that soil fungal communities are highly responsive to changes in soil moisture within and across years (Hawkes et al. 2011). These responses translate to changes in fungal abundance, community composition, and further to function. Perhaps somewhat surprisingly, Hawkes et al. 
(2011) concluded that fungal communities during low soil moisture were more diverse and abundant than during high soil moisture. Furthermore, these responses in fungal communities were rapid, reversible, and repeatable, thus highlighting the community plasticity in terms of possessed environmental or physiological tolerances (Cruz-Martinez et al. 2009). The community dynamics resulting from the rapid changes in soil moisture preceding and following rainfall pulse events may mask the long-term dynamics of fungal responses to available soil moisture (Hawkes et al. 2011; Cregger et al. 2012). Such short term dynamics on the scale of days are further overlaid by seasonal dynamics in soil moisture that further drive the soil fungal community structure and function (Hawkes et al. 2011; Cregger et al. 2012). Fundamentally, soil moisture is a pivotal driver of fungal biomass (Frey et al. 1999) and the communities respond rapidly to changes in available moisture.

Environmental change factors do not operate in isolation. Predicting the interactions among multiple drivers is problematic based on single driver experiments (Shaw et al. 2002; Larsen et al. 2011). Therefore, concerted manipulations of multiple environmental drivers are essential. The primary goal of this contribution was to utilize an existing experiment that has simultaneously manipulated temperature and precipitation timing in a tallgrass prairie ecosystem (Fay et al. 2000, 2002, 2003). Previous studies using this experimental infrastructure have observed responses in plant growth and aboveground annual net primary production (ANPP) (Knapp et al. 2002; Fay et al. 2011), leaf carbon assimilation (Fay et al. 2011), soil $\mathrm{CO}_{2}$ efflux (Harper et al. 2005; Fay et al. 2011; Zeglin et al. 2013), as well as soil microbial community biomass and exoenzyme activities (Zeglin et al. 2013). Collectively, these studies have observed that the longterm manipulation of the rainfall frequency has increased the amplitude of the intraannual soil moisture variability reducing the average soil water availability (Fay et al. 2011) leading to reduced rainfall use efficiency (Fay et al. 2011) and to reduced soil microbial community carbon use efficiency (Zeglin et al. 2013). The elevated temperature treatments in turn have advanced plant phenology in spring, increased winter soil $\mathrm{CO}_{2}$ efflux, and reduced summer soil $\mathrm{CO}_{2}$ efflux (Fay et al. 2011). These 
treatments have also shifted the biomass allocation among the major plant functional groups via reduction of forb ANPP (Fay et al. 2011). In sum, the effects of elevated temperature seem to differ between cooler and warmer seasons and have major consequences on fundamental ecosystem processes. These studies also highlight the shifting relative importance of the temperature and rainfall manipulations: early in the growing season the ecosystem processes were most strongly driven by the elevated temperature, whereas the precipitation manipulations and the resultant variability in the soil moisture had more pronounced effects later in the season (Fay et al. 2011).

To elucidate compositional responses of the soil fungal communities, we analyzed fungal Internal Transcribed Spacer (ITS) regions from samples collected from this ongoing experiment via high throughput sequencing in combination with samplespecific DNA tagging. This allowed taking advantage of a well-replicated experiment and testing hypotheses on responses of fungal diversity and community composition to the environmental manipulations and their interactions. We hypothesized that fungal communities - their diversity, richness, and composition will change due to alterations in the frequency - but not in the amount - of precipitation, changes in temperature, and/or the combination of these two environmental drivers. These studies were strongly motivated by our previous results (Zeglin et al. 2013) that suggest that the microbial communities are dynamic on multiple temporal scales functionally and compositionally, but did not specifically target specific compositional constituents of the fungal communities. 


\section{Materials and Methods}

\section{Site description}

The study was conducted at the Konza Prairie Biological Station (KPBS, $39^{\circ} 05^{\prime} \mathrm{N}$, 96 35’ W), a Long-Term Ecological Research (LTER) site representative of native tallgrass prairie in the Flint Hills of eastern Kansas, USA. KPBS spans 3,487 ha, and the vast majority of the site remains undisturbed by agriculture. The vegetation is dominated by native $\mathrm{C}_{4}$ grasses: big bluestem (Andropogon gerardii), indian grass (Sorghastrum nutans), little bluestem (Schizachyrium scoparium) and switch grass (Panicum virgatum) (for a complete list of vascular plants at the KPBS, see Towne 2002). The Flint Hills are generally characterized by shallow soils overlaying chertbearing limestones and shales (Ransom et al. 1998) and our site is classified as typical chernozern according to the Food and Agriculture Organizations (FAO) soils classification used by the United Nations. Topographic relief divides the landscape into upland plateaus with shallow soils, slopes with outcrops of limestone, and lowlands with deeper alluvial and colluvial soils. January mean temperature is $-3^{\circ} \mathrm{C}$ (range -9 to $3^{\circ} \mathrm{C}$ ) and the July mean is $27^{\circ} \mathrm{C}$ (range 20 to $33^{\circ} \mathrm{C}$ ). Annual precipitation averages $835 \mathrm{~mm}, 75 \%$ of which falls in the growing season between April and October.

\section{Rainfall Manipulation Plots (RaMPs)}

The RaMPs experiment was established in 1997 and has been operational since May of 1998. Twelve sheltered RaMPs and three non-sheltered reference plots are located on a gently sloping (1-2\%) site with relatively deep $(75-120 \mathrm{~cm}$ to limestone) Irwin silty clay loams (fine, mixed, mesic Pachic Argiustolls). Because shelters reduce midday photon flux density by ca. 18\% and may thus impact photosynthesis and carbon flow into the soil, the present study excluded the nonsheltered reference plots and the experimental design considers only the twelve sheltered RaMPs. The experimental site is managed by annual spring burning (typically in late March), a common management practice that controls woody vegetation and generally enhances productivity of the dominant perennial grasses. 
Each RaMP comprises a fixed-location, 14 x $9 \mathrm{~m}$ rainout shelter over intact, native grassland (Fay et al. 2000, 2003). Each shelter consists of a clear (UV transparent) polyethylene roof to exclude natural rainfall, two $4 \mathrm{~m}^{3}$ reservoirs to collect and store up to $10 \mathrm{~cm}$ of rainfall, and an overhead irrigation system to reapply (at $2.5 \mathrm{~cm} \mathrm{hr}^{-1}$ ) the stored rainfall. Thus, the shelter design allows for complete and efficient experimental control of the quantity, timing and variability in rainfall inputs (Fay et al. 2000). Rainfall is applied to each RaMP using 13 sprinkler heads to ensure uniform application over each plot. A subset of the RaMPs contains micrometeorological stations for comparison with unsheltered plots. Each shelter covers a central 6 × $6 \mathrm{~m}$ sampling area, with a substantial surrounding buffer ( $0.8 \mathrm{~m}$ wide). A $1.2 \mathrm{~m}$ deep subsurface barrier limits lateral water movement into and out of each experimental plot. The large rainout shelter size relative to the plot size is effective at minimizing lateral (windblown) rainfall inputs to the central sampling area, and soil moisture in the plots vary independently from the surroundings (Fay et al. 2000).

\section{Precipitation and Temperature Treatments}

The RaMPs experiment has proceeded in phases outlined in detail in Fay et al. (2011). From 1998 to 2001, the RaMPs were assigned to one of four rainfall treatments in a completely randomized block design (4 RaMP treatments + one reference plot in each of three blocks). Treatments were factorial combinations of two within-season temporal rainfall distribution patterns (ambient or altered rainfall timing, detailed below) combined with two growing season rainfall quantities (100\% or $70 \%$ of natural rainfall amounts). These manipulations occur only during the growing season, when $>75 \%$ of the annual precipitation falls. In 2002 , the simple drought treatment (30\% reduction in quantity) was eliminated (see Fay et al. 2002, 2003 for detailed analyses including the drought treatments) to increase sample size for the rainfall timing manipulations $(n=6)$ and to prepare for the addition of the warming treatments. The former drought treatment plots retained their prior rainfall timing treatment (ambient or altered timing), but since 
2002 after elimination of the drought treatment, all plots - controls as well as the altered interval plots - receive an amount equal to $100 \%$ of ambient rainfall quantities. In spring 2003, two $4 \mathrm{~m}^{2}$ temperature manipulation plots were installed in each RaMP (and each non-sheltered reference plot), modifying the experiment to a split-plot design, with precipitation as the whole-plot treatment and warming as the subplot treatment. The final split-plot design comprises two precipitation treatments each with six replicates (2002). Each RaMPs plot includes four heat treatment plots (since 2003) - two heated plots, one ambient temperature plot with a non-heated lamp structure and one control plot where no structure has been installed. Thus, the experiment allows for assessing the impacts of increased temperature and altered rainfall as well as their interactive effects.

In the present study, a total of four treatment combinations were included; (1) Ambient precipitation regime: In six of the twelve RaMPs, collected rainfall is reapplied to the plots each time a natural rainfall event occurs. Rain gauges outside the RaMPs and an in-line flowmeter allow confirmation that precipitation amounts applied inside the RaMPs equal the amounts of rain falling outside. (2) Altered precipitation regime: The remaining six RaMPs receive a treatment that imposes a predicted rainfall regime of increased temporal variability in rainfall inputs and soil moisture relative to ambient precipitation patterns. This is achieved by lengthening the current ambient dry intervals between rainfall events by $50 \%$. For example, a 2week period between ambient rainfall events would be lengthened to 3 weeks. Any rainfall during these experimentally lengthened dry periods is stored and applied as a single larger event at the end of the dry interval. The total amount of growing season rainfall applied in this treatment is identical to ambient, only the event size and temporal distribution of inputs are altered. For the purposes of the experiment, an event is defined as precipitation $>5 \mathrm{~mm}$ in a $24 \mathrm{hr}$ period. Lesser amounts are almost entirely intercepted by the canopy (Seastedt 1985). A 50\% increase in dry intervals was based on analyses of 20+ years of growing season rainfall patterns at Konza Prairie from which the average storm size and frequency was calculated and deviations assessed. This analysis ensured that the treatment selected resulted in a 
rainfall regime fundamentally altered from typical ambient patterns. (3) and (4) Increased air and soil temperatures with ambient or altered rainfall patterns: Each RaMP is divided into four 2 × 2 m subplots. Overhead rectangular IR lamps (Kalglo MRM-1215 1500-W model) are suspended at ca. $1.5 \mathrm{~m}$ above the canopy in two subplots, whereas one subplot serves as a blank lamp control and another subplot as a no-treatment control. The lamps simulate climate warming increasing day (0.4$\left.0.6^{\circ} \mathrm{C}\right)$ and night $\left(1.0-1.5^{\circ} \mathrm{C}\right)$ canopy temperatures as well as soil temperatures (annual mean $\sim 1^{\circ} \mathrm{C}$ at $5 \mathrm{~cm}$ soil depth) by enhancing downward IR flux ( $\left.\sim 70 \mathrm{~W} \mathrm{~m}^{-2}\right)$ (Fay et al. 2011). In contrast to rainfall treatments, warming occurs year round. While any experimental warming approach has its limitations, IR lamps are a widely used, and are a preferred option, for warming experiments under field conditions (Shaver et al. 2000). We raise the lamps during the growing season as vegetation height increases to maintain a constant IR flux at the canopy surface, and avoid unrealistic radiation loads on the canopy. For the analyses described here, we selected one elevated temperature treatment and its corresponding control in each of the twelve RaMPs canopies (total of 24 experimental units).

\section{Soil sampling and DNA extraction}

For each experimental unit (six replicates for each of the four experimental conditions), two $2.5 \mathrm{~cm}$ diameter $10 \mathrm{~cm}$ deep cores were collected in June 2006, pooled, and homogenized. From each composite sample, visible roots and large rocks were removed and genomic DNA was extracted from a $10 \mathrm{~g}$ subsample using a standard soil DNA extraction kit (UltraClean Mega Soil DNA Kit, MoBio, Carlsbad, CA). After extraction, the DNA was diluted to $\sim 5 \mathrm{ng}^{-1}{ }^{-1}$ and stored at $-80^{\circ} \mathrm{C}$.

\section{Amplification and 454-sequencing of the Internal Transcribed Spacer}

The extracted DNA was used to amplify soil fungal communities using primers with a bias towards fungi (ITS1 and ITS2; White et al.1990) designed to amplify the highly variable Internal Transcribed Spacer 1 (ITS1). To allow direct 454sequencing, we synthesized primer constructs which incorporated the 454-primers 
(Margulies et al. 2005) similarly to Jumpponen \& Jones (2009). Between the 454and ITS1 primers, we included a 5-bp DNA-tag unique to each experimental unit (Supplemental Table S1).

To amplify the fungal ITS1, the PCR reactions [ $5 \mu$ l of Green GoTaq Flexi PCR buffer (Promega, Madison, Wisconsin), $2.5 \mathrm{mM} \mathrm{MgCl}_{2}, 200 \mu \mathrm{M}$ dNTP, $0.2 \mu \mathrm{M}$ each forward and reverse primers, one unit GoTaq Hot Start DNA polymerase, and 5ng soil extracted DNA] were run for 25 cycles at $94^{\circ} \mathrm{C}$ for $1 \mathrm{~min}, 54^{\circ} \mathrm{C}$ for $1 \mathrm{~min}, 72^{\circ} \mathrm{C}$ for 2 min, and a final 10 min extension at $72^{\circ} \mathrm{C}$ on MasterCyclers (Eppendorf, Hamburg, Germany). From each sample, the fungal ITS was amplified in three separate reactions, individual reactions pooled, and cleaned using an AmPure PCR cleanup kit (Agencourt Bioscience, Beverly, MA). One sample failed amplification and was omitted from further analyses. A total of $100 \mathrm{ng}$ of each differentially DNA-tagged PCR product were pooled and sequenced on a GS20 genome sequencer at 454 Life Sciences (Branford, CT). The data are available through Sequence Read Archive (BioProject PRJNA219046; BioSamples SAMN02351567 - SAMN02351589).

\section{Bioinformatics and OTU designation}

The sequence data were analyzed as previously described (Jumpponen \& Jones, 2009). Briefly, sequences were removed if they contained no valid primer sequence or DNA tag, contained ambiguous bases, or were outside of the set length threshold of $85 \mathrm{bp}$ to $130 \mathrm{bp}$. The remaining reads were aligned with CAP3 (Huang \& Madan, 1999) and assigned to operational taxonomic units (OTUs) at $97 \%$ similarity. The data were parsed by sample to calculate the OTU frequencies and counts for each sample. From this output, SAS (SAS Institute Inc., Cary, NC) was used to calculate richness and diversity indices as previously described (Jumpponen \& Jones, 2009). We estimated a number of diversity indexes (Table 1; $\mathrm{S}_{\mathrm{Obs}}$ - observed number of OTUs; Simpson's D; Shannon's H'; Fisher's $\alpha$; and, evenness based on the ratio of Shannon's H' and the natural logarithm of the richness). To further explore organismal coverage, species accumulation (Mao Tau rarefaction) curves were 
generated using EstimateS (Colwell 2006). Although we were tempted to estimate the extrapolative richness metrics, our analyses indicated that our sampling depth was inadequate for meaningful extrapolative estimators (see Simpson's D in Table 1).

OTU frequencies were analyzed based on OTUs assigned at $97 \%$ sequence similarity and the singletons omitted as recommended by Tedersoo et al. (2010). The nonsingleton OTUs were analyzed as a proxy for species-level resolution for treatment effects in SAS (SAS Institute, Cary, NC). Student's t-test ( $\alpha=0.05$ for hypothesis $\mathrm{f}(\mathrm{OTU})>0$ ) was used to identify OTUs whose frequencies were either too low or too variable to provide meaningful inferences on their responses to treatments. The taxon affinities for fungal OTUs were based on BLAST queries (Zhang et al. 2000) against nt database (Supplemental Table S2). To minimize the number of environmental "unculturable fungus" matches to our queries with fungal sequences, we additionally applied an Entrez limit (Eukarya[ORGANISM] NOT environmental samples[FILTER] NOT unculturable[ALL FIELDS]) (Supplemental Table S3). To provide a broader taxonomic context, all non-singleton OTUs were assigned to classes based on the fungal lineage information for the top ranked matches among the ten that were retrieved from BLAST queries. The class-level resolution was chosen to increase classification recovery with the short ( $<130 \mathrm{bp}$ ), partial ITS1 reads (see Porter and Golding 2011). For these analyses, the OTU frequencies were summed for each experimental unit and taxon, and analyzed for treatment effects.

\section{Statistical analyses}

Data were tested for normality and homogeneity of variance (Milliken and Johnson 1984). Observed variance heterogeneity was corrected through $\log _{10}$ transformation. The main (Warming, Precipitation) and interactive (Warming*Precipitation) effects were analyzed in JMP (SAS Institute Inc., Cary, NC) The effects "Block", "RaMP(Precipitation)" and "RaMP(Warming,Precipitation)" 
were considered random effects in the mixed model analysis of variance (ANOVA). We also examined taxon (class, OTU) level responses. For the analyses on the level of a class, the OTU frequencies were summed for each experimental unit and taxon, and analyzed for treatment effects using mixed models ANOVA. To limit the number of OTUs considered in these analyses, we included only those OTUs that occurred on average at frequencies significantly greater than zero (Student's $t$-test; $\alpha=0.05$ for null hypothesis $\mathrm{f}(\mathrm{OTU})=0$ ); these analyses identified a total of 226 OTUs that were analyzed using the mixed models ANOVA as described above. To minimize the risk of Type I errors, we used False Discovery Rate (FDR) correction to identify classes and OTUs most likely to respond to the experimental manipulations. To examine community-level differences, the OTU frequencies were analyzed using Nonmetric Multidimensional Scaling (NMS) in PC-ORD (Version 4.1, McCune and Mefford 1999). Because the low frequency OTUs may have disproportionate effects on these ordination analyses, we omitted OTUs that did not occur in at least six (or 25\%) of the experimental units. Pairwise community distances were estimated using Sørensen index and analyzed using Nonmetric Multidimensional Scaling (NMS, Mather 1976). The optimal number of dimensions (k) was selected based on Monte Carlo test of significance at each level of dimensionality comparing 40 runs with empirical data against 50 randomized runs with a step-down in dimensionality from 6 to 1 and a random seed starting value. Three-dimensional solution $(\mathrm{k} \geq 3)$ yielded stress values smaller than those in randomized runs $(P=0.0196)$ and was selected for final configuration. To estimate the treatment level responses of the communities the axis scores were analyzed in JMP (SAS Institute Inc., Cary, NC) as described above. 


\section{Results}

General data description

To characterize soil fungal communities, a total of 45,564 sequences that passed the quality control were analyzed. More than $20 \%$ of the total sequence yield was omitted because of missing primer or DNA-tag sequences, length $(<85$ or $>130 \mathrm{bp})$, or ambiguous nucleotides.

The sequences were assigned to a total of 1,642 fungal OTUs, 315 of which occurred only once in the dataset. Excluding groups that had no clear taxonomic affinities, these OTUs represented a total of 19 classes and 62 orders. The data were strongly dominated by Agaricomycetes (Basidiomycota; 56\% of the sequences) followed by Eurotiomycetes (Ascomycota; 9.7\%) and Leotiomycetes (Ascomycota; 6.1\%); 7.4\% of the sequences could not be assigned to a class (Fig. 1; Supplemental Table S4). The eleven most common classes that were present in an excess of $1 \%$ of the total sequencing yield constituted more than $99 \%$ of the acquired sequences with the exception of unknown sequences (7.4\%). Although taxonomic information is desirable, it is necessary to exercise caution with these taxon assignments as the GS20-generated short reads presented a challenge for OTU taxon assignments, especially in less inclusive taxonomic ranks below order level (Porter and Golding 2011). Examination of the average bit scores (92.1 \pm 40.8$)$, e-values (9.1 x 10-8 \pm 7.9 $\left.x 10^{-7}\right)$, and coverage ( $56.4 \pm 26.3$ ) indicate considerable uncertainty in the taxon placement based on these data. However, when the most common OTUs were examined in more detail, they were consistently placed in the same phylum and class suggesting that these assignments are likely to represent correct affinities. The inconsistencies that we observed were likely results from misidentified or erroneously annotated reads in the database (see Jumpponen \& Jones 2010 for more detailed discussion). 
The initial analyses indicated that the total number of sequences per experimental unit varied across the treatments: there was a significant interaction $\left(\mathrm{F}_{1,10}=5.56, P\right.$ $=0.0421$ ) between the warming and altered precipitation treatments (Tables 1 and 2). The sequence yields in the control treatment (ambient precipitation and ambient temperature) were higher than in the experimentally warmed treatments under ambient precipitation regime. Because differing sampling intensities may lead to bias and erroneous conclusions (Gihring et al. 2011), the data were analyzed with equalization of the sampling effort (1,095 random sequences were subsampled per experimental unit). Rarefaction analyses indicated that the sampling effort was inadequate to saturate the organismal richness in these samples (Fig 2). After subsampling, the observed OTU richness, diversity estimators and evenness were insensitive to the experimental manipulations and did not differ significantly among the treatments (Tables 1 and 2).

\section{Taxon responses to the environmental manipulations}

To explore the overall community responses, OTU frequencies were analyzed using NMS ordination after omission of the infrequent OTUs (OTUs that occurred in $<6$ plots). This lead to a dataset with 211 OTUs that were best resolved in $\mathrm{k} \geq 3$ dimensions. Fungal communities were unresponsive to the experimental manipulations and the treatments were indistinguishable in these NMS analyses (Fig 3). To provide an estimate of organismal responses, those fungal OTUs that were abundant and invariable enough (based on $t$-tests at $\alpha=0.05$ ) were selected for further analyses. The $t$-tests identified a total of 226 among the 1,327 nonsingleton OTUs that occurred on average at frequencies significantly greater than zero. Overall, 16 of these OTUs (7.1\%) showed significant responses to the experimental treatments or their interaction. After correcting for multiple comparisons (FDR), none of these responses remained significant (Supplemental Table S5). 
To provide a taxonomic framework for organismal responses to altered precipitation and experimental warming, the fungal OTUs were analyzed at a level of a class (Fig 4). These analyses provide broad scale information on the organismal responses to treatments. Among the nineteen fungal classes detected in our samples, only Lecanoromycetes were responsive and decreased in frequency in the warming treatment (Supplemental Tables S6 and S7). Similarly, Leotiomycetes seemed to be marginally responsive to precipitation manipulations and Tremellomycetes marginally responsive to warming and the interaction between warming and precipitation (Fig 4). However, none of these responses were significant after the FDR-correction for multiple comparisons. 


\section{Discussion}

Our current study aimed to test hypotheses on fungal community richness, diversity, and compositional responses to manipulations of the precipitation frequency as well as temperature in a long-term experiment in a tallgrass prairie ecosystem. One of the greatest advantages of using the RaMPs study is its long duration - a minimum of four growing seasons of altered precipitation interval treatments and three growing seasons of warming treatments at the time of sampling for the current study. Studies reported here were motivated by previous research efforts that have reported plant community (Knapp et al. 2002), process level (Harper et al. 2005; Fay et al. 2011) shifts and changes in plant (Fay et al. 2011) or microbial community function (Fay et al. 2011; Zeglin et al. 2013) as a result of experimental manipulation of environmental conditions in the course of the RaMPs experiments. Those studies reported that the plant communities characteristic of the lowland deep soils had shifted towards communities that resemble the more xeric upland communities as a result of the precipitation manipulations and the resultant lower water availability? (Knapp et al. 2002; Fay et al. 2002; 2003). Other ecosystem properties have also responded to these manipulations. Most importantly, $\mathrm{C}$ cycling as measured by $\mathrm{CO}_{2}$ flux was observed to be?tightly correlated with soil moisture (Harper et al. 2005; Zeglin et al. 2013). Those previous studies also suggest that soil $\mathrm{CO}_{2}$ flux, plant $\mathrm{CO}_{2}$ uptake, and the plant-utilized C?(inferred from ANPP) are all reduced by altered?timing or reduced quantity of rainfall (Fay et al. 2003; 2011; Harper et al. 2005). These ecosystem process level responses coincide with shifts in microbial biomass and activity (Evans \& Wallenstein 2012; Zeglin et al. 2013) that seem reversible if the soil moisture conditions are homogenized across the long-term treatments (Evans \& Wallenstein 2012). The observed above and belowground responses suggest that both the loss of $\mathrm{C}$ from? soil as well as $\mathrm{CO}_{2}$ capture by the plant? community may be reduced by lower soil moisture, but partly compensated by the extension of metabolic activity by warming treatments (Fay et al. 2011). If ANPP reductions are not fully offset by the reduced soil $\mathrm{CO}_{2}$ fluxes in the increased rainfall interval 
treatments then this would lead to an increased net $\mathrm{C}$ sequestration over time. Zeglin et al. (2013) proposed that changes in microbial activities and biomass in the altered precipitation interval treatments could partly be reduced or compensated by more stress tolerant microbial communities that maintain growth at lower water potentials. Our current study specifically examined whether the soil inhabiting fungal communities would have changed compositionally and whether those shifts would coincide with the previously observed functional shifts.

Our data suggest that soil fungal communities remain largely unaltered and are resilient to experimental warming, manipulation of precipitation intervals, or their combination - leading thus to rejection of our original hypotheses. The fungal communities showed very few responses - particularly after accounting for multiple comparisons - regardless of whether the community composition was analyzed for responses of individual OTUs or for overall community distinction among treatments, or considered in terms of community summary statistics such as the richness or diversity. Our observations are consistent with some previous studies (Papanikolaou et al. 2010; Gutknecht et al. 2012; Anderson et al. 2013) but in contrast with others (Allison \& Treseder 2008; Castro et al. 2010; Deslippe et al. 2011; Hayden et al. 2012). Our results suggest that: (1) soil communities are unresponsive to environmental manipulations; (2) the resident communities may adapt to the changing environmental conditions (Malcolm et al. 2008); or (3) the soil communities are adequately plastic to withstand environmental extremes (Cruz-Martinez et al. 2009; Hawkes et al. 2011) exaggerated by the experimental manipulations. It remains unclear whether our studies suffer from poor statistical power as high replication is difficult to achieve in large-scale experimental manipulations. However, previous studies have observed clear responses to these manipulations (Fay et al. 2003; Harper et al. 2005; Zeglin et al. 2013), suggesting therefore that the fungal community responses are likely to be lesser in scale.

Both soil temperature (Hacskaylo et al. 1965; Malcolm et al. 2008) and moisture (Frey et al. 1999) are important drivers of fungal growth, metabolism and 
physiology. Yet, the effects of these drivers on fungal communities remain unclear and studies often yield contrasting results (Bardgett et al. 1999; Compant et al. 2010). Interpretation of soil community responses may be further complicated by indirect effects of plant communities (Cregger et al. 2012; Anderson et al. 2013), temporal dynamics that may take place on multiple time scales (Hawkes et al. 2011; Cregger et al. 2012; Zeglin et al. 2013), ecosystem level differences (Compant et al. 2010), or interacting environmental drivers (Hayden et al. 2012). Our data provide no support for strong soil fungal community responses to environmental manipulations in the RaMPs experiment, despite a relatively long manipulation of the environmental conditions. In comparison, many warming studies take place for a few months in growth chambers (e.g., Büscher et al. 2012; Anderson et al. 2013) and precipitation manipulations are limited to few growing seasons (e.g., Cregger $e t$ al. 2012; Krashevska et al. 2012). More extensive manipulations (e.g., manipulation of precipitation over 5 years in Hawkes et al. 2011 and manipulation of $\mathrm{CO}_{2}$ and temperature for 5 years in Hayden et al. 2012) provide an experimental platform to address environmental change effects in more relevant time scales. However, community turnover may mask fungal responses to environmental manipulations (Cregger et al. 2012), as fungal community responses may be rapid, reversible and repeatable (Hawkes et al. 2011). Taken together, it is important to tie fungal community analyses to a short-term temporal context that permit assessment of dynamics suggesting plastic environmental tolerances (Cruz-Martinez et al. 2009). Our experiments targeted long-term responses to environmental manipulations and did not address short-term temporal dynamics.

Studies that aim to address interacting environmental change drivers are few and complex to interpret; partly because responses tend not to be additive (Shen et al. 2009; Hayden et al. 2012; Matias et al. 2012), partly because interacting environmental drivers may exaggerate the environmental extremes. Hayden et al. (2012) analyzed soil bacterial, archaeal and fungal responses to elevated $\mathrm{CO}_{2}$, elevated temperature and their interaction. They found that the soil organisms responded differently to the two environmental factors and their interaction. Fungi 
were divided into three distinct groups based on ambient $\mathrm{CO}_{2}$, elevated $\mathrm{CO}_{2}$, or when elevated $\mathrm{CO}_{2}$ was combined with experimental warming. These authors concluded that taxa responded differently under elevated $\mathrm{CO}_{2}$ or warming and that response under any one condition could not be used to predict responses to interacting environmental drivers. In our study, we observed no obvious responses to increased precipitation intervals, elevated temperature, or their combination. This is unexpected as previous studies show that the altered precipitation intervals lower the average water potential (Harper et al. 2005; Fay et al. 2011), thus controlling soil function (Harper et al. 2005; Zeglin et al. 2013) as well as above ground productivity (Fay et al. 2011). Given the responses in function, we would have expected concomitant community responses, because elevated temperature may accelerate microbial metabolism (Rustad et al. 2001; Melillo et al. 2002; Shen et al. 2009) or increase substrate availability in soil (Stromgren \& Linder 2002; Pendall et al. 2004). Simultaneously, available soil moisture - or lack thereof - sets inhibitory boundaries (Sheik et al., 2011) even if the temperature might still be within the optimal range for the resident soil organisms. Such conditions may lead to communities that are more resilient or stress tolerant (Zeglin et al. 2013). Based on our data, soil fungal communities in a seasonally dynamic mesic grassland system that undergoes frequent periodic low water potentials and high soil temperatures are well buffered and incorporate adequate environmental plasticity to withstand the extremes created by interacting environmental drivers.

We also assessed potential taxon (class, OTU) responses to experimental manipulations. The taxon assignments of the short GS20 reads should be considered with caution (Nilsson et al. 2009; Vilgalys 2003). However, we compared the ranking of classes in this study to those reported previously in the same tallgrass prairie site (Jumpponen et al. 2010). Consistent with the previous studies, the soil fungal communities are dominated strongly by Agaricomycetes and Eurotiomycetes. In contrast to the relatively high proportion of Leotiomycetes in the present study, Leotiomycetes were relatively infrequent in the previous study and outranked by Dothideomycetes, Sordariomycetes and Lecanoromycetes. On the coarse class-level 
resolution, we saw minimal responses to our experimental manipulations. Notwithstanding, while the database assigned taxonomic affinities even to the coarsest levels of taxonomic hierarchy may be inaccurate, OTUs represent mathematical creatures and differences - or lack there of - among them are independent of taxonomic hierarchy. Consistent with the diversity and richness estimators, the OTU level responses in our dataset were few and none were supported after correction for multiple comparisons. We also specifically examined OTUs assigned to Glomeromycota, the phylum known to form arbuscular mycorrhizas. Despite the removal of most roots prior to DNA extraction, approximately 3\% of the sequences represented Glomeromycota. These data likely represent extramatrical hyphae and spores, or small root fragments that could not be removed from the clayey soil matrix. Our analyses suggest that despite the reported responses in the above (Fay et al. 2002; 2003) or below ground processes (Harper et al. 2005; Zeglin et al. 2013), there were no strong responses to the experimental manipulations among the arbuscular mycorrhizal symbionts. Only one Glomeromycotan OTU (OTU717) seemed responsive $(P=0.0308)$ to the interaction between warming and precipitation prior to, but not after, FDR-corrections (Supplemental Table S5).

Our GS20 data are burdened by some potential problems. First, pooling of amplicons across the experimental treatments was inaccurate and necessitated corrections for sampling effort (see also Ghiring et al. 2011). Second, the short GS20-generated 454sequences provided a poor taxonomic framework. However, even if the taxonomic classification of the acquired sequence data may prove inadequate, the OTU assignments based on sequence similarities provide an estimate of organismal responses (Liu et al. 2008). Similarly, since community analyses based on the relative OTU frequencies neither require nor rely on approximation of taxon affinities, the estimates of the community turnover are likely reliable. These issues are important when considering adoption of ultra-high-throughput next-generation sequencing technologies that provide enormous data volumes but relatively short reads (Porter \& Golding 2011; Caporaso et al. 2012; Brown et al. 2013). Finally, the 
sequencing depth did not approach saturation of the organismal richness as suggested by our rarefaction analyses. However, successful saturation of the organismal richness in an analysis of soil microbial communities may be unattainable in studies seeking statistical power instead of most accurate species richness estimate (see Buée et al. 2009; Roesch et al. 2007). Furthermore, we chose to use the relative frequencies of common and abundant OTUs in our compositional analyses as reliance on the infrequent taxa may exaggerate observed community richness or differences therein. The use of frequent - or core (Magurran \& Henderson 2003) - taxa provides reasonable estimates of the community compositional shifts. Sequencing data may also have a greater resolution or somewhat different view of the resident communities than DNA fingerprinting (e.g. Hayden et al. 2012) or phospholipid fatty acid (e.g. Gutknecht et al. 2012) tools employed in other recent studies.

The stability of the fungal communities may be explained by the microbial persistence in soil even at low water potentials as well as by their ability to respond and gain function rapidly even after small precipitation events (Schwinning \& Sala 2004). Overall, across a variety of ecosystems, soil function has been shown to respond rapidly to wetting events as indicated by the soil $\mathrm{CO}_{2}$ efflux (Liu et al. 2002; Fierer \& Schimel 2003; Smart \& Penuelas 2005; Sponseller 2007; Chou et al. 2008; Chen et al. 2009; Zeglin et al. 2013) suggesting that resident, metabolically inactive organisms rapidly gain their metabolic and physiological activities after unfavorable environmental conditions. Combining warming treatments with manipulation of precipitation may further exaggerate loss of water from the soil profile (Sheik et al. 2011) and therefore reduce the periods of metabolic activity. However, we have no evidence for fungal community responses to combined manipulation of precipitation intervals and temperature in this study. It is possible that repeated sampling or sampling targeting pulse events would prove more informative for identifying community responses to environmental manipulations.

The stability of communities in a mesic tallgrass prairie ecosystem is perhaps not 
completely unexpected. Ecosystems and environments with large seasonal variability in precipitation can buffer the effects of climate change because a broad range of environmental and physiological tolerances likely exist in the resident microbial communities (Cruz-Martinez et al. 2009; Hawkes et al. 2011). Alternatively, in such environments, environmental change may exaggerate the severity of variation or increase the frequency of extreme events, leading to distinct communities under the predicted future environmental conditions (Hawkes et al. 2011). Our results support the former view. However, we emphasize that these soil community responses to precipitation may be strongly influenced by seasonal and pulse dynamics. For example, Chou et al. (2008) reported that soil $\mathrm{CO}_{2}$ fluxes did not respond to rainfall during the wet season, whereas the fluxes increased rapidly and strongly in the early, drier season wet-up events. These findings are consistent with Zeglin et al. (2013), who observed rapid community responses to pulsed wetting events in the RaMPs experiment. The short-term and seasonal dynamics likely mask community responses to experimental manipulations. For example, Cregger et al. (2012) reported that seasonal community dynamics far exceeded the responses to experimental precipitation treatments in a piñon-juniper woodland highlighting the importance of including either multiple sampling occasions or controlling for the available soil moisture at the time of sampling. Additionally, use of a more labile marker such as rRNA may be suitable for targeting the community dynamics in temporally more appropriate context.

It is likely that in a mesic tallgrass prairie ecosystem, where most of the precipitation falls during the growing season, responses of microbial communities fueled by changes in long-term shifts in soil water potentials remain small. This is not to say that the function of those communities remains unaltered. Previous results from this study system indicate that alterations in precipitation lead to reduced soil respiration (Harper et al. 2005; Fay et al. 2011) raising the possibility of functional changes that remain uncorroborated in our compositional analyses of the soil communities. A portion of the $\mathrm{CO}_{2}$ response observed in those studies may 
also be an autotrophic response, as the fluxes were measured under field conditions with intact plant root systems.

What are the functional consequences of environmental change in the long term based on our current study? Bardgett et al. (2008) reviewed soil community contributions and their importance as a carbon interface between terrestrial and atmospheric carbon pools. While studies on ANPP, many ecosystem functions, and soil community function or activity (Fay et al. 2011; Zeglin et al. 2013) have highlighted the shifts resulting from the environmental manipulations in the RaMPs experiment, our data suggest that the soil fungal communities are largely unresponsive to manipulations of precipitation frequency and elevated temperature. Perhaps the most important conclusion emerging from these studies is that the soil communities may be structurally buffered against interacting environmental change drivers, whereas their function is determined by environmental constraints - available soil moisture in particular. Our concurrent studies on soil community carbon dynamics suggest that the measured activities decline with reduced soil moisture, leading to greater carbon storage at least in short-term (Zeglin et al. 2013). The tight coupling of above and below ground processes (Bardgett et al. 2008) necessitate estimating the whole ecosystem carbon budget that establish whether the tallgrass systems serve as net sinks or sources in the face of changing environments. 


\section{Acknowledgements}

This research was funded in part by the Ecological Genomics Institute at Kansas State University. U.S. Department of Energy's Office of Science (BER) through the Midwestern Regional Center of the National Institute for Climatic Change Research at Michigan Technological University funded the RaMPs program. Konza Prairie LTER provided access to the tallgrass prairie sites. John Blair provided helpful comments on the manuscript and provided access to the RaMPs experiment. 


\section{References}

Adams JM, Faure H, Faure-Denard L, McGlade JM, Woodward FI, 1990. Increases in terrestrial carbon storage from the Last Glacial Maximum to the present. Nature 348: 711-714.

Allison SD, McGuire KL, Treseder KK, 2010. Resistance of microbial and soil properties to warming treatment seven years after boreal fire. Soil Biology \& Biochemistry 42: 1872-1878.

Allison SD, Treseder KK, 2008. Warming and drying suppress microbial activity and carbon cycling in boreal forest soils. Global Change Biology 14: 2898-2909.

Anderson IC, Drigo B, Keniry K, Ghannoum O, Chambers SM, Tissue DT, Cairney JWG, 2013. FEMS Microbiology Ecology 83: 425-437.

Austin A, Yahdjian L, Stark J, Belnap J, Porporato A, Norton U, Ravetta D, Schaeffer S, 2004. Water pulses and biogeochemical cycles in arid and semiarid ecosystems. Oecologia 141: 221-235

Baldrian P, Merhautová V, Petránková M, Cajthaml T, Snajdr J, 2010. Distribution of microbial biomass and activity of extracellular enzymes in a hard- wood forest soil reflect soil moisture content. Applied Soil Ecology 46: 177-182.

Bardgett RD, Freeman C, Ostle NJ, 2008. Microbial contributions to climate change through carbon cycle feedbacks. ISME Journal 2: 805-814.

Bardgett RD, Kandeler E, Tsherko D, Hobbs PJ, Bzemer TM, Jones TH, Thompson LJ, 1999. Below-ground microbial community development in a high temperature world. Oikos 85: 193-203. 
Bell CW, Acosta-Martinez V, McIntyre N, Cox S, Tissue DT, Zak JC, 2009. Linking microbial community structure and function to seasonal differences in soil moisture and temperature in a Chihuahuan Desert grassland. Microbial Ecology 58: 827-842.

Bond-Lamberty B, Wang C, Gower ST, 2004. A global relationship between the heterotrophic and autotrophic components of soil respiration? Global Change Biology 10: 1756-1766.

Brockett BFT, Prescott CE, Grayston SJ, 2012, Soil moisture is the major factor influencing microbial community structure and enzyme activities across seven bioclimatic zones in western Canada. Soil Biology and Biochemistry 44: 9-20.

Brown SP, Oliver AK, Callaham MA, Jumpponen A, 2013. Deep Ion Torrent sequencing identifies soil fungal community shifts after frequent prescribed fires in a southeastern US forest ecosystem. FEMS Microbiology Ecology In Press

Buée EL, Reich M, Murat C, Morin E, Nilsson RH, Uroz S, Martin F, 2009. 454 pyrosequencing analyses of forest soils reveal an unexpectedly high fungal diversity. New Phytologist 184: 449-456.

Büscher M, Zavalloni C, de Boulois HD, Vicca S, van den Berge J, Declerck S, Ceulemans R, Janssens IA, Nijs I, 2012. Effects of arbuscular mycorrhizal fungi on grassland productivity are altered by future climate and below-ground resource availability. Environmental and Experimental Botany 81: 62-71.

Caporaso, JG, Lauber CL, Walters WA, Berg-Lyons D, Huntley J, Fierer N, Owens SM, Betley J, Fraser L, Bauer M, Gormley N, Gilbert JA, Smith G, Knight R, 2012. Ultrahigh-throughput microbial community analusis on the Illumina HiSeq and MiSeq platforms. ISME Journal 6: 1621-1624.

Carbone MS, Still CJ, Ambrose AR, Dawson TE, Williams AP, Boot CM, Schaeffer SM, 
Schimel JP, 2011. Seasonal and episodic moisture controls on plant and microbial contributions to soil respiration. Oecologia 167: 265-278.

Castro HF, Classen AT, Austin EE, Norby RJ, Schadt CW, 2010. Soil microbial community responses to multiple experimental climate change drivers. Applied and Environmental Microbiology 76: 999-1007.

Chen S, Lin Gm Huang J, Jenerette D, 2009. Dependence of carbon sequestration on the differential responses of ecosystem photosynthesis and respiration to rain pulses in a semiarid steppe. Global Change Ecology 15: 2450-2461.

Chou WW, Silver WL, Jackson RD, Thompson AW, Allen-Diaz B, 2008. The sensitivity of annual grassland carbon cycling to the quantity and timing of rainfall. Global Change Biology 14: 1382-1394.

Clark J, Campbell J, Grizzle H, Acosta-Martinez V, Zak J, 2009. Soil microbial community response to drought and precipitation variability in the Chihuahuan Desert. Microbial Ecology 57: 248 -260.

Clemmensen KE, Michelsen A, Jonasson S, Shaver GR, 2006. Increased ectomycorrhizal fungal abundance after long-term fertilization and warming of two arctic tundra ecosystems. New Phytologist 171: 391-404.

Colwell RK, 2006. EstimateS: statistical estimation of species richness and shared species from samples. Version 8. http://viceroy.eeb.uconn.edu/estimates

Compant S, van der Heijden MGA, Sessitsch A, 2010. Climate change effects on beneficial plant-microorganism interactions. FEMS Microbiology Ecology 73: 197214.

Cregger MA, Shadt CW, McDowell NG, Pockman WT, Classen AT, 2012. Response of 
the soil microbial community to changes in precipitation on a semiarid ecosystem. Applied and Environmental Mircobiology 78: 8587-8594.

Cruz-Martinez K, Suttle KB, Brodie EL, Power ME, Andersen GL, Banfield JF, 2009. Despite strong seasonal responses, soil microbial consortia are more resilient to long-term changes in rainfall than overlying grassland. ISME Journal, 3, 738-744.

Davidson EA, Janssens IA, 2006. Temperature sensitivity of soil carbon decomposition and feedbacks to climate change. Nature 440: 165-173.

Deslippe JR, Hartmann M, Mohn WW, Simard SW, 2011. Long-term experimental manipulation alters the ectomycorrhizal community of Betula nana in Arctic tundra. Global Change Biology 17: 1625-1636.

Dighton J, 2003. Fungi in ecosystem processes. Marcel Decker, New York.

Drigo B, Kowalchuk GA, van Veen JA, 2008. Climate change goes underground: effects of elevated $\mathrm{CO}_{2}$ on microbial community structure and activities in the rhizopshere. Biology and Fertility of Soils 44: 667-679.

Evans SE, Wallenstein MD, 2012. Soil microbial community response to drying and rewetting stress: does historical precipitation regime matter? Biogeochemistry 109: 101- 116.

Fay PA, Carlisle JD, Knapp AK, Blair JM, Collins SL, 2000. Altering rainfall timing and quantity in a mesic grassland ecosystem: design and performance of rainfall manipulation shelters. Ecosystems 3: 308-319.

Fay PA, Carlisle JD, Danner BT, Lett MS, McCarron JK, Stewart C, Knapp AK, Blair JM, Collins SL, 2002. Altered rainfall patterns, gas exchange, and growth of grasses and forbs. International Journal of Plant Sciences 163: 549-557. 
Fay PA, Carlisle JD, Knapp AK, Blair JM, Collins SL, 2003. Productivity responses to altered rainfall patterns in a C-4-dominated grassland. Oecologia 137: 245-251.

Fay PA, Blair JM, Smith MD, Nippert JB, Carlisle JD, Knapp AK, 2011. Relative effects of precipitation variability and warming on tallgrass prairie ecosystem function. Biogeosciences 8:3053-3068.

Fierer N, Schimel JP, 2003. A proposed mechanism for the pulse in carbon dioxide production commonly observed following the rapid rewetting of a dry soil. Soil Science Society of America Journal 67: 798-805.

Fierer N, Schimel JP, Holden PA, 2003. Influence of drying-rewetting frequency on soil bacterial community structure. Microbial Ecology 45: 63-71.

Frey SD, Drijber R, Smith H, Melillo J, 2008 Microbial biomass, functional capacity, and community structure after 12 years of soil warming. Soil Biology and Biochemistry 40: 2904-2907.

Frey SD, Elliott ET, Paustian K, 1999. Bacterial and fungal abundance and biomass in conventional and no-tillage agroecosystems along two climatic gradients. Soil Biology and Biochemistry 31: 573-585.

Gao Q, Reynolds JF, 2003. Historical shrub-grass transitions in the northern Chihuahuan desert: modeling the effects of shifting rainfall seasonality and event size over a landscape gradient. Global Change Biology 9: 1475-1493.

Gihring TM, Green SJ, Schadt CW, 2011. Massively parallel rRNA gene sequencing exacerbates the potential for biased community diversity comparisons due to variable library sizes. Environmental Microbiology 14: 285-290. 
Gray SB, Classen AT, Kardol P, Yermakov Z, Miller RM, 2011. Multiple ?climate change factors interact to alter soil microbial community structure tin an old-field ecosystem. Soil Science Society of America Journal 75: 2217-2226.

Gutknecht JLM, Field CB, Balser TC, 2012. Microbial communities and their responses to simulated global change fluctuate greatly over multiple years. Global Change Biology 18: 2256-2269.

Hacskaylo E, Palmer JG, Vosso JA, 1965. Effects of temperature on growth and respiration of ectotrophic mycorrhizal fungi. Mycologia 57: 748-756.

Hanson PJ, Edwards NT, Garten CT, Andrews JA, 2000. Separating root and soil microbial contributions to soil respiration: a review of methods and observations. Biogeochemistry 48: 115-146.

Harper CW, Blair JM, Fay PA, Knapp AK, Carlisle JD, 2005. Increased rainfall variability and reduced rainfall amount decreases soil CO2 flux in a grassland ecosystem. Global Change Biology 11: 322-334.

Hawkes CV, Hartley IP, Ineson P, Fitter AH, 2008. Soil temperature affects carbon allocation within arbuscular mycorrhizal networks and carbon transport from plant to fungus. Global Change Biology 14: 1181-1190.

Hawkes CV, Kivlin SN, Rocca JD, Huguet V, Thomsen MA, Suttle KB, 2011. Fungal community responses to precipitation. Global Change Biology 17: 1637-1645.

Hayden HL, Mele PM, Bougoure DS, Allan CY, Norng S, Piceno YM, Brodie EL, DeSantis TZ, Andersen GL, Williams AM, Hovenden MJ, 2012. Changes in the microbial community structure of bacteria, archaea and fungi in response to elevated $\mathrm{CO}_{2}$ and warming in an Australian native grassland soil. Environmental Microbiology 14: 3081-3096. 
Heinemeyer A, Ineson P, Ostle N, Fitter AH, 2006. Respiration of the external mycelium in the arbuscular mycorrhizal symbiosis shows strong dependence on recent photosynthates and acclimation to temperature. New Phytologist 171: 159170.

Huang XQ, Madan A, 1999. CAP3: A DNA sequence assembly program. Genome Research 9: 868-877.

Huxman TE, Snyder KA, Tissue D, Leffler AJ, Ogle K, Pockman WT, Sandquist DR, Potts DL, Schwinning S, 2004. Precipitation pulses and carbon fluxes in semiarid and arid ecosystems. Oecologia 141: 254-268.

Intergovernmental Panel on Climate Change (IPCC) 2007. IPCC Fourth Assessment Report - Climate Change 2007: The Physical Science Basis. Cambridge University Press, Cambridge.

Jumpponen A, Jones KL, 2009. Massively parallel 454 sequencing indicates hyperdiverse fungal communities in temperate Quercus macrocarpa phyllosphere. New Phytologist 184: 438-448.

Jumpponen, A. and Jones, K.L. 2010. Seasonally dynamic fungal communities in Quercus macrocarpa phyllosphere differ among urban and rural environments. New Phytologist 186: 496-513

Jumpponen A, Jones KL, Blair J, 2010. Vertical distribution of fungal communities in tallgrass prairie soil. Mycologia 102: 1027-1041.

Knapp AK, Beier C, Briske DD, Claassen AT, Luo Y, Reichstein M, Smith MD, Smith SD, Bell JE, Fay PA, Heisler JL, Leavitt SW, Sherry R, Smith B, Weng E, 2008. Consequences of more estreme precipitation regimes for terrestrial ecosystems. 
Bioscience 58: 811-821.

Knapp AK, Fay PA, Blair JM, Collins SL, Smith MD, Carlisle JD, Harper CW, Danner BT, Lett MS, McCarron JK, 2002. Rainfall variability, carbon cycling, and plant species diversity in a mesic grassland. Science 298: 2202-2205.

Knapp AK, Smith MD, 2001. Variation among biomes in temporal dynamics of aboveground primary production. Science 291: 481-484.

Krashevska V, Sandmann D, Maraun M, Scheu S, 2012. Consequences of exclusion of precipitation on microorganisms and microbial consumers in montane tropical rainforests. Oecologia 170: 1067-1076.

Lal R, 2004. Soil carbon sequestration to mitigate climate change. Geoderma 123: 122.

Larsen KS, Andresen LC, Beier C, Jonasson S, Albert KR, Ambus P, Arndal MF, Carter MS, Christensen S, Holmstrup M, Ibrom A, Kongstad J, van der Linden L, Maraldo K, Michelsen A, Mikkelsen TN, Pilegaard K, Prieme A, Ro-Poulsen H, Schmidt IK, Selsted $\mathrm{MB}$, Stevnbak K, 2011. Reduced $\mathrm{N}$ cycling in response to elevated $\mathrm{CO}_{2}$, warming, and drought in a Danish heathland: syn- thesizing results of the CLIMAITE project after two years of treatments. Global Change Biology 17: 1884-1899.

Liu ZZ, DeSantis TZ, Andersen GL, Knight R, 2008. Accurate taxonomy assignments from 16S rRNA sequences produced by highly parallel pyrosequencers. Nucleic Acids Research 36: e120

Liu X, Wan S, Su B, Hui D, Luo Y, 2002. Response of soil CO2 efflux to water manipulation in tall grass prairie ecosystem. Plant and Soil 240: 213-223.

Magurran A, Henderson P, 2003. Explaining the excess of rare species in natural 
species abundance distributions. Nature 422: 714-716.

Malcolm GM, López-Gutiérrez JC, Koide RT, Eissenstat DM, 2008. Acclimation to temperature and temperature sensitivity of metabolism by ectomycorrhizal fungi. Global Change Biology 14: 1169-1180.

Margulies M, Egholm M, Altman WE, Attiya S, Bader JS, Bemben LA, Berka J, Braverman MS, Chen YJ, Chen ZT, Dewell SB, Du L, Fierro JM, Gomes XV, Godwin BC, He W, Helgesen S, Ho CH, Irzyk GP, Jando SC, Alenquer MLI, Jarvie TP, Jirage KB, Kim JB, Knight JR, Lanza JR, Leamon JH, Lefkowitz SM, Lei M, Li J, Lohman KL, Lu H, Makhijani VB, McDade KE, McKenna MP, Myers EW, Nickerson E, Nobile JR, Plant R, Puc BP, Ronan MT, Roth GT, Sarkis GJ, Simons JF, Simpson JW, Srinivasan M, Tartaro KR, Tomasz A, Vogt KA, Volkmer GA, Wang SH, Wang Y, Weiner MP, Yu PG, Begley $\mathrm{RF}$, Rothberg JM, 2005. Genome sequencing in microfabricated high-density picolitre reactors. Nature 437: 376-380.

Mather PM, 1976. Computational methods of multivariate analysis in physical geography. London: J Wiley \& Sons. 532 p.

Matias L, Castro J, Zamora R, 2012. Effect of simulated climate change on soil respiration in a Mediterranean-type ecosystem: rainfall and habitat type are more important that temperature or the soil carbon pool. Ecosystems 15: 299-310.

McCune B, Mefford MJ, 1999. PC-ORD multivariate analysis of ecological data. Version 4.1. Glendale Beach, Oregon: MjM Software.

Melillo JM, Steudler PA, Aber JD, Newkirk K, Lux H, Bowles FP, Catricala C, Magill A, Ahrens T, Morrisseau S, 2002. Soil warming and carbon-cycle feedbacks to the climate system. Science 298: 2173-2176.

Milliken GA, Johnson DE, 1984. Analysis of messy data. 1, Designed experiments. Van 
Nostrand Reinhold, New York, NY.

Nazih N, Finlay-Moore O, Hartel PG, Fuhrmann JJ, 2001. Whole soil fatty acid methyl ester (FAME) profiles of early soybean rhizosphere as affected by temperature and matric water potential. Soil Biology and Biochemistry 33: 693- 696.

Nilsson RH, Ryberg M, Abarenkov K, Sjokvist E, Kristiansson E, 2009. The ITS region as a target for characterization of fungal communities using emerging sequencing technologies. FEMS Microbiology Letters 296:97-101.

Ogle K, Reynolds JF, 2004. Plant responses to precipitation in desert ecosystems: integrating functional types, pulses, thresholds, and delays. Oecologia 141: 282-294.

Olsrud M, Carlsson BÅ, Svensson BM, Michelsen A, Melillo JM, 2010. Responses of fungal root colonization, plant cover and leaf nutrients to long-term exposure to elevated atmospheric $\mathrm{CO} 2$ and warming in a subarctic birch forest understory. Global Change Biology 16: 1820-1829.

Papanikolaou N, Britton AJ, Helliwell RC, Johnson D, 2010. Nitrogen deposition, vegetation burning and climate warming act independently on microbial community structure and enzyme activity associated with decomposing litter in low-alpine heath. Global Change Biology 16: 3120-3132.

Pendall E, Bridgham S, Hanson PJ, Hungate B, Kicklighter DW, Johnson DW, Law BE, Luo YQ, Megonigal JP, Olsrud M, Ryan MG, Wan SQ, 2004. Below-ground process responses to elevated $\mathrm{CO} 2$ and temperature: a discussion of observations, measurement methods, and models. New Phytologist 162: 311-322.

Porter TM, Golding GB, 2011. Are similarity- or phylogeny-based methods more appropriate for classifying internal transcribed sparer (ITS) metagenomic 
amplicons? New Phytologist 192: 775-782.

Raich JW, Schlesinger WH, 1992. The global carbon dioxide flux in soil respiration and its relationship to vegetation and climate. Tellus 44B: 81-99.

Ransom MD, Rice CW, Todd TC, Wehmueller WA, 1998. Soils and soil biota. In: Knapp AK, Briggs JM, Hartnett DC, Collins SL, eds. Grassland dynamics: long-term ecological research in tallgrass prairie. New York: Oxford. p 48-67.

Rinnan R, Michelsen A, Bååth E, Jonasson S, 2007. Fifteen years of climate change manipulations alter soil microbial communities on a subarctic heath ecosystem. Global Change Biology 13: 28-39.

Roesch LF, Fulthorpe RR, Riva A, Gasella G, Hadwin AKM, Kent AD, Daroub SH, Camargo FAO, Farmerie WG, Triplett EW, 2007. Pyrosequencing enumerates and contrasts soil microbial diversity. ISME Journal 1:283-290.

Rustad LE, Campbell JL, Marion GM, Norby RJ, Mitchell MJ, Hartley AE, Cornelissen JHC, Gurevitch J, 2001. A meta-analysis of the response of soil respiration, net nitrogen mineralization, and aboveground plant growth to experimental ecosystem warming. Oecologia 126: 543-562.

Rygiewicz PT, Martin KJ, Tuininga AR, 2000. Morphotype community structure of ectomycorrhizas on Douglas fir (Pseudotsuga menziesii Mirb. Franco) seedlings grown under elevated atmospheric CO2 and temperature. Oecologia 124: 299-308.

Schmitt A, Glaser B, 2011. Organic matter dynamics in a temperate forest soil following enhanced drying. Soil Biology \& Biochemistry 43: 478-489.

Schwinning S, Sala OE, 2004. Hierarchy of responses to resource pulses in arid and semi-arid ecosystems. Oecologia 141: 211-220. 
Seastedt TR, 1985. Canopy interception of nitrogen in bulk precipitation by annually burned and unburned tallgrass prairie. Oecologia 66: 88-92.

Shaver GR, Canadell J, Chapin FS III, Gurevitch J, Harte J, Henry G, Ineson P, Jonasson S, Melillo J, Pitelka L, Rustad L, 2000. Global warming and terrestrial ecosystems: a conceptual framework for analysis. Bioscience 50: 871-882.

Shaw MR, Zavaleta ES, Chiariello NR, Cleland EE, Mooney HA, Field CB, 2002. Grassland responses to global environmental changes suppressed by elevated $\mathrm{CO}_{2}$. Science 298: 1987-1990.

Sheik CS, Beasley WH, Elshahed MS, Zhou XH, Luo YQ, Krumholz LR, 2011. Effect of warming and drought on grassland microbial communities. ISME Journal 5: 16921700.

Shen W, Reynolds JF, Hui D, 2009. Responses of dryland soil respiration and soil carbon pool size to abrupt vs. gradual and individual vs. combined changes in soil temperature, precipitation, and atmospheric [ $\left[\mathrm{CO}_{2}\right]$ : a simulation analysis. Global Change Biology 15: 2274-2294.

Skopp J, Jawson MD, Doran JW, 1990. Steady-state aerobic microbial activity as a function of soil water content. Soil Science Society of America Journal 54: 1619-1625.

Smart DR, Penuelas J, 2005. Short-term $\mathrm{CO}_{2}$ emissions from planted soil subject to elevated $\mathrm{CO}_{2}$ and simulated precipitation. Applied Soil Ecology 28: 247-257.

Sponseller RA, 2007. Precipitation pulses and soil $\mathrm{CO}_{2}$ flux in a Sonoran Desert ecosystem. Global Change Biology 13: 426-436.

Staddon PL, Thompson K, Jakobsen I, Grime JP, Askew AP, Fitter AH, 2003. 
Mycorrhizal fungal abundance is affected by long-term climatic manipulations in the field. Global Change Biology 9: 186-194.

Stromgren M, Linder S, 2002. Effects of nutrition and soil warming on stemwood production in a boreal Norway spruce stand. Global Change Biology 8: 1195-1204.

Swemmer AM, Knapp AK, Snyman HA, 2007. Intra-seasonal precipitation patterns and above-ground productivity in three perennial grasslands. Journal of Ecology 95 : 780-788.

Tedersoo L, Nilsson RH, Abarenkov K, Jairus T, Sadam A, Saar I, Bahram M, Bechem E, Chuyong G, Köljag U, 2010. 454 pyrosequencing and Sanger sequencing of tropical mycorrhizal fungi provide similar results but reveal substantial methodo- logical biases. New Phytologist 188: 291-301.

Toberman H, Freeman C, Evans C, Fenner N, Artz RRA, 2008. Summer drought decreases soil fungal diversity and associated phenol oxidase activity in upland Calluna heathland soil. FEMS Microbiology Ecology 66: 426-436.

Towne EG, 2002. Vascular plants of Konza Prairie Biological Station: an annotated checklist of species in a Kansas tallgrass prairie. Sida 20: 269-294.

Treseder KK, Allen MF, 2000. Mycorrhizal fungi have a potential role in soil carbon storage under elevated $\mathrm{CO} 2$ and nitrogen deposition. New Phytologist 147: 189-200.

Vilgalys R, 2003. Taxonomic misidentification in public DNA databases. New Phytologist 160: 4-5.

Wan S, Luo Y, 2003. Substrate regulation of soil respiration in a tall grass prairie: results of a clipping and shading experiment. Global Biogeochemical Cycles 17: 
e1054, doi: 10.1029/2002GB001971.

Wan S, Luo Y, Wallace LL, 2002. Changes in microclimate induced by experimental warming and clipping in tallgrass prairie. Global Change Biology 8: 754-768.

Weltzin JF, Loik ME, Schwinning S, Williams DG, Fay PA, Haddad BM, Harte J, Huxman TE, Knapp AK, Lin GH, Pockman WT, Shaw MR, Small EE, Smith MD, Smith SD, Tissue DT, Zak JC, 2003. Assessing the response of terrestrial ecosystems to potential changes in precipitation. Bioscience 53: 941-952.

White TJ, Bruns TD, Lee SB, Taylor JW, 1990. Amplification and direct sequencing of fungal ribosomal RNA genes for phylogenetics. In: Innis MA, Gelfand DH, Sninsky JJ, White TJ, eds. PCR protocols: a guide to methods and applications. New York: Academic Press. P. 315- 325.

Xu L, Baldocchi DD, Tang J, 2004. How soil moisture, rain pulses, and growth alter the response of ecosystem respiration to temperature. Global Biogeochemical Cycles 18: eGB4002, doi: 10.1029/2004GB002281.

Zeglin LH, Bottomley PJ, Jumpponen A, Rice CW, Arango M, Lindsey A, McGowan A, Mfombep P, Myrold DD, 2013. Altered precipitation regime alters the function and composition of soil microbial communities on multiple time scales. Ecology In Press.

Ziegler SE, Billings SA, Lane CS, Li J, Fogel ML, 2013. Warming alters routing of labile and slower-turnover carbon through distinct microbial groups in boreal forest organic soils. Soil Biology and Biochemistry 60: 23-32.

Zhang W, Parker KM, Luo Y, Wan S, Wallace LL, 2005. Soil microbial responses to experimental warming and clipping in a tallgrass prairie. Global Change Biology 11: 266-277. 
Zhang Z, Schwartz S, Wagner L, Miller W, 2000. A greedy algorithm for aligning DNA sequences. Journal of Computational Biology 7: 203-214. 


\section{FIGURE LEGENDS}

Fig 1 - Distribution of the GS20-derived sequences across fungal classes for all samples in the RaMPs study. The chart shows the reads assigned to most common classes ( $>1 \%$ ) as a proportion of all acquired sequences. Unknown sequences did not return a phylum level classification in our BLAST queries. Group "Other" includes Agaricostilbomycetes ( $0.01 \%$ of all sequences), Chytridiomycetes $(0.03 \%)$, Entomophthoromycotina (0.04\%), Microbotryomycotina (1\%), Neocallimastigomycetes $(0.06 \%)$, Orbiliomycetes $(0.09 \%)$, Pucciniomycetes $(0.04 \%)$, Tremellomycetes $(0.11 \%)$, Ustilaginomycetes $(0.11 \%)$.

Fig 2 - Rarefaction (Mao Tau) analysis of fungal communities in the RaMPs experiment manipulating the precipitation intervals and temperatures. $\mathrm{P}=$ extended precipitation interval, $\mathrm{W}=$ experimental warming, $\mathrm{W} \times \mathrm{P}=\mathrm{W}$ and $\mathrm{P}$ treatments combined. Horizontal lines show the treatment means. Text box on the upper left corner lists treatment means \pm standard deviations. Vertical line shows the subsampling level for the richness and diversity estimators.

Fig 3 - Nonmetric Multidimensional Scaling (NMS) ordination of the fungal community data in the RaMPs experiment manipulating the precipitation intervals and temperatures (mean axis score \pm standard deviation). Percentages on axes show the proportion of the variance represented. Inserts provide the mixed model ANOVA tables testing treatment differences for each of the axes: $\mathrm{P}=$ extended precipitation interval, $\mathrm{W}=$ experimental warming, $\mathrm{W} \times \mathrm{P}=\mathrm{W}$ and $\mathrm{P}$ treatments combined. $P$-values for the $F$-test values: ns $-P>0.05$.

Fig 4 - Rank ordered responses of fungi on a class level to manipulation of precipitation intervals and experimental warming (mean \pm standard deviation). While most fungal classes show no significant response, Lecanoromycetes increase in frequency in response to experimental warming. This response is not significant after correction for multiple comparisons. 
